Nianyuan Tan*, Shuisheng Wu, Donghui Lan, Chak-Tong Au and Bing Yi*

\title{
Crystal structure of $5 \mathrm{H}$-dibenzo[c,f][1,5] oxabismocin-12 (7H)-yl acetate, $\mathrm{C}_{16} \mathrm{H}_{15} \mathrm{O}_{3} \mathrm{Bi}$
}

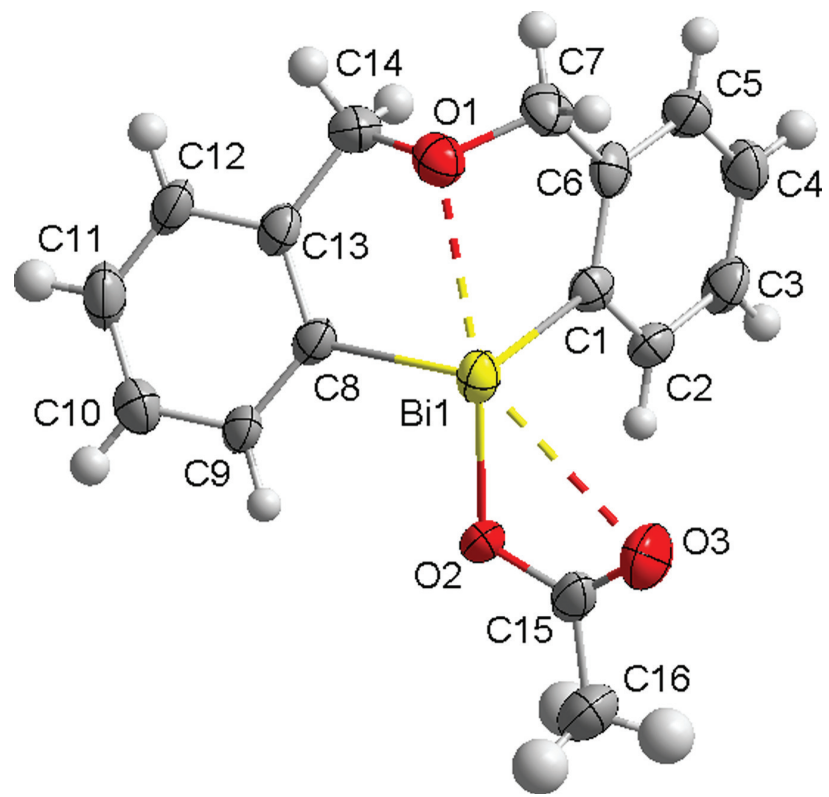

https://doi.org/10.1515/ncrs-2019-0825

Received November 11, 2019; accepted December 12, 2019;

available online January 8,2020

\section{Abstract \\ $\mathrm{C}_{16} \mathrm{H}_{15} \mathrm{O}_{3} \mathrm{Bi}$, orthorhombic, Pna2 $2_{1}$ (no. 33), $a=17.277$ (3) $\AA$, $b=4.7288(8) \AA, \quad c=17.776(3) \AA, \quad V=1452.3(4) \AA^{3}, \quad Z=4$, $R_{\mathrm{gt}}(\mathrm{F})=0.0292, w R\left(F^{2}\right)=0.0678, T=296 \mathrm{~K}$.}

CCDC no.: 1886916

The molecular structure is shown in the figure. Tables 1 and 2 contain details on crystal structure and measurement conditions and a list of the atoms including atomic coordinates and displacement parameters.

*Corresponding authors: Nianyuan Tan and Bing Yi, Hunan Provincial Key Laboratory of Environmental Catalysis and Waste Regeneration, College of Materials and Chemical Engineering, Hunan Institute of Engineering, Xiangtan 411104, China, e-mail: nytan@sina.com (N. Tan), bingyi2005@126.com (B. Yi). https://orcid.org/0000-0001-7925-0405 (N. Tan)

Shuisheng Wu, Donghui Lan and Chak-Tong Au: Hunan Provincial Key Laboratory of Environmental Catalysis and Waste Regeneration, College of Materials and Chemical Engineering, Hunan Institute of Engineering, Xiangtan 411104, China
Table 1: Data collection and handling.

\begin{tabular}{ll}
\hline Crystal: & Rodlike, colorless \\
Size: & $0.24 \times 0.12 \times 0.06 \mathrm{~mm}$ \\
Wavelength: & Mo $K \alpha$ radiation $(0.71073 \AA)$ \\
$\mu:$ & $12.14 \mathrm{~mm}^{-1}$ \\
Diffractometer, scan mode: & Bruker APEX-II, $\varphi$ and $\omega$-scans \\
$\theta_{\text {max }}$, completeness: & $26.4^{\circ},>99 \%$ \\
$N\left(h k l_{\text {measured }}, N(h k l)_{\text {unique }}, R_{\text {int }}:\right.$ & $13322,2925,0.041$ \\
Criterion for $I_{\text {obs }}, N\left(h k l l_{\mathrm{gt}}:\right.$ & $I_{\text {obs }}>2 \sigma\left(I_{\text {obs }}\right), 2697$ \\
$N(\text { param })_{\text {refined }}:$ & 182 \\
Programs: & Bruker programs [1], SHELX [2, 3]
\end{tabular}

Table 2: Fractional atomic coordinates and isotropic or equivalent isotropic displacement parameters $\left(\AA^{2}\right)$.

\begin{tabular}{lrrrr}
\hline Atom & $\boldsymbol{x}$ & $\boldsymbol{y}$ & $\boldsymbol{z}$ & $\boldsymbol{U}_{\text {iso }}{ }^{*} \boldsymbol{U}_{\text {eq }}$ \\
\hline Bi1 & $0.19495(2)$ & $0.84302(5)$ & $0.52398(4)$ & $0.03465(13)$ \\
O1 & $0.2919(4)$ & $0.8698(13)$ & $0.4138(5)$ & $0.0419(18)$ \\
O2 & $0.1217(4)$ & $0.5831(17)$ & $0.6013(4)$ & $0.0406(16)$ \\
O3 & $0.1697(6)$ & $0.8829(19)$ & $0.6841(5)$ & $0.067(2)$ \\
C1 & $0.3029(5)$ & $0.6053(18)$ & $0.5549(6)$ & $0.030(2)$ \\
C2 & $0.3087(5)$ & $0.412(2)$ & $0.6147(6)$ & $0.033(2)$ \\
H2 & 0.264774 & 0.365076 & 0.642290 & $0.040^{*}$ \\
C3 & $0.3789(6)$ & $0.291(2)$ & $0.6330(5)$ & $0.042(2)$ \\
H3 & 0.381799 & 0.158334 & 0.671582 & $0.050^{*}$ \\
C4 & $0.4455(7)$ & $0.3676(19)$ & $0.5935(6)$ & $0.046(3)$ \\
H4 & 0.493171 & 0.291307 & 0.606891 & $0.056^{*}$ \\
C5 & $0.4407(5)$ & $0.5556(19)$ & $0.5348(8)$ & $0.041(2)$ \\
H5 & 0.485423 & 0.602972 & 0.508533 & $0.049^{*}$ \\
C6 & $0.3711(5)$ & $0.6765(14)$ & $0.5139(7)$ & $0.035(3)$ \\
C7 & $0.3650(7)$ & $0.8847(19)$ & $0.4500(6)$ & $0.043(2)$ \\
H7A & 0.372842 & 1.074555 & 0.469253 & $0.052^{*}$ \\
H7B & 0.405524 & 0.846185 & 0.413675 & $0.052^{*}$ \\
C8 & $0.1573(6)$ & $0.5423(18)$ & $0.4330(5)$ & $0.032(2)$ \\
C9 & $0.0858(5)$ & $0.409(2)$ & $0.4351(5)$ & $0.0344(19)$ \\
H9 & 0.053677 & 0.435516 & 0.476480 & $0.041^{*}$ \\
C10 & $0.0612(6)$ & $0.237(2)$ & $0.3761(7)$ & $0.046(2)$ \\
H10 & 0.013386 & 0.147559 & 0.378420 & $0.055^{*}$ \\
C11 & $0.1078(7)$ & $0.202(2)$ & $0.3152(7)$ & $0.052(3)$ \\
H11 & 0.091405 & 0.086759 & 0.276026 & $0.063^{*}$ \\
C12 & $0.1779(7)$ & $0.3331(19)$ & $0.3104(6)$ & $0.045(3)$ \\
H12 & 0.208435 & 0.310523 & 0.267721 & $0.054^{*}$ \\
C13 & $0.2037(5)$ & $0.5025(18)$ & $0.3705(6)$ & $0.035(2)$ \\
C14 & $0.2840(7)$ & $0.626(2)$ & $0.3652(7)$ & $0.048(3)$ \\
H14A & 0.321654 & 0.483382 & 0.379629 & $0.057^{*}$ \\
H14B & 0.294423 & 0.680323 & 0.313642 & $0.057^{*}$ \\
& & & & \\
& & & &
\end{tabular}


Table 2 (continued)

\begin{tabular}{lrrrr}
\hline Atom & $\boldsymbol{x}$ & $\boldsymbol{y}$ & $\boldsymbol{z}$ & $\boldsymbol{U}_{\text {iso }}{ }^{*} / \boldsymbol{U}_{\text {eq }}$ \\
\hline C15 & $0.1267(6)$ & $0.685(2)$ & $0.6685(6)$ & $0.044(2)$ \\
C16 & $0.0783(8)$ & $0.543(4)$ & $0.7273(7)$ & $0.073(4)$ \\
H16A & 0.025539 & 0.603474 & 0.722529 & $0.110^{*}$ \\
H16B & 0.097354 & 0.592215 & 0.776352 & $0.110^{*}$ \\
H16C & 0.081107 & 0.341467 & 0.720865 & $0.110^{*}$ \\
\hline
\end{tabular}

\section{Source of material}

The compound $\mathrm{O}\left(\mathrm{CH}_{2} \mathrm{C}_{6} \mathrm{H}_{4}\right)_{2} \mathrm{BiCl}$ is prepared by a literature known synthesis [4]. To a solution of $\mathrm{O}\left(\mathrm{CH}_{2} \mathrm{C}_{6} \mathrm{H}_{4}\right)_{2} \mathrm{BiCl}$ $(0.265 \mathrm{~g}, 0.6 \mathrm{mmol})$ in $20 \mathrm{~mL} \mathrm{CH}_{2} \mathrm{Cl}_{2}$, a suspension of $\mathrm{CH}_{3} \mathrm{CO}_{2} \mathrm{Ag}(0.110 \mathrm{~g}, 0.66 \mathrm{mmol})$ in $10 \mathrm{~mL}$ distilled water was added. The reaction mixture was stirred in the dark at room temperature for $24 \mathrm{~h}$ and then filtered. The organic phase was separated, washed with water and dried over anhydrous $\mathrm{Na}_{2} \mathrm{SO}_{4}$. After filtered, removal of the organic solvent under vacuum gave the title compound $\mathrm{O}\left(\mathrm{CH}_{2} \mathrm{C}_{6} \mathrm{H}_{4}\right)_{2} \mathrm{BiO}_{2} \mathrm{CCH}_{3}$. Crystals were obtained by crystallization from $\mathrm{CH}_{2} \mathrm{Cl}_{2} / n$ hexane. ${ }^{1} \mathbf{H}$ NMR (400 MHz, $\mathrm{CDCl}_{3}$, TMS): $\delta=8.16(4 \mathrm{H}, \mathrm{d}$, $J=7.2 \mathrm{~Hz}), 7.54(4 \mathrm{H}, \mathrm{t}, J=7.6 \mathrm{~Hz}), 7.41(4 \mathrm{H}, \mathrm{d}, J=7.6 \mathrm{~Hz})$, $7.27(4 \mathrm{H}, \mathrm{t}, J=7.2 \mathrm{~Hz}), 5.21(4 \mathrm{H}, \mathrm{d}, J=13.6 \mathrm{~Hz}), 4.80(4 \mathrm{H}, \mathrm{d}$, $J=13.6 \mathrm{~Hz}), 2.31$ (3H, s) ppm; ${ }^{13} \mathbf{C}$ NMR $\left(\mathrm{CDCl}_{3}, 100 \mathrm{MHz}\right.$, TMS): $\delta=178.51,145.15,136.98,131.34,127.77,127.25,77.66$, $22.79 \mathrm{ppm}$.

\section{Experimental details}

The methylene and aromatic $\mathrm{H}$ atoms were generated geometrically and refined using the riding model with $U_{\text {iso }}(\mathrm{H})$ set to $1.2 U_{\text {eq }}(\mathrm{C})$. The methyl $\mathrm{H}$ atoms were allowed, rotate with a fixed angle around the $\mathrm{C}-\mathrm{C}$ bond to best fit the experimental electron density with $U_{\text {iso }}(\mathrm{H})$ set to $1.5 U_{\text {eq }}(\mathrm{C})$ and $\mathrm{C}-\mathrm{H}=0.96 \AA$.

\section{Comment}

Over recent years there has been an increasing interest in the chemistry of the hypervalent organobismuth compounds having intramolecular $\mathrm{N}, \mathrm{O}, \mathrm{S} \rightarrow \mathrm{Bi}$ coordination owing to their novel structure chemistry and use in areas such as organic synthesis, catalysis and medicine [4-13]. To the best of our knowledge, only one hypervalent organobismuth acetate with intramolecular $\mathrm{N}, \mathrm{O}, \mathrm{S} \rightarrow \mathrm{Bi}$ interactions, i.e. $\left[2,6-\left(\mathrm{Me}_{2} \mathrm{NCH}_{2}\right) \mathrm{C}_{6} \mathrm{H}_{3}\right] \mathrm{Bi}\left(\mathrm{O}_{2} \mathrm{CCH}_{3}\right)_{2}$, has been reported so far [9].

The asymmetric unit of the title structure contains one complete molecule (cf. the figure). In the molecular structure of organobismuth acetate, $\mathrm{O}\left(\mathrm{CH}_{2} \mathrm{C}_{6} \mathrm{H}_{4}\right)_{2} \mathrm{BiO}_{2} \mathrm{CCH}_{3}$, the transannular interaction between the bismuth atom and the oxygen atom is observed, and the Bi1-01 distance [2.581(8) $\AA$ ] is longer than those of the organobismuth halide, nitrate and cation with the 5,6,7,12-tetrahydrodibenz [c,f][1,5]oxabismocine framework, i.e. $\quad \mathrm{O}_{(}\left(\mathrm{CH}_{2} \mathrm{C}_{6} \mathrm{H}_{4}\right)_{2} \mathrm{BiCl}$ (2.543(6) $\AA$ ) [10], [O $\left.\left(\mathrm{CH}_{2} \mathrm{C}_{6} \mathrm{H}_{4}\right)_{2} \mathrm{Bi}\right] \mathrm{NO}_{3}(2.508(2) \AA)$ [10], and $\left[\mathrm{O}\left(\mathrm{CH}_{2} \mathrm{C}_{6} \mathrm{H}_{4}\right)_{2} \mathrm{Bi}\left(\mathrm{OH}_{2}\right)\right]^{+}\left[\mathrm{SO}_{3} \mathrm{CF}_{3}\right]^{-}$(2.417(7) $\AA$ ) [4], indicating that the $\mathrm{O} \rightarrow \mathrm{Bi}$ coordination of the latter is slightly stronger than that of the former, and shorter than those of the organobismuth carbonate with same framework, i.e. $\left[\mathrm{O}\left(\mathrm{CH}_{2} \mathrm{C}_{6} \mathrm{H}_{4}\right)_{2} \mathrm{Bi}_{2} \mathrm{CO}_{3}\right.$ [2.587(4) and 2.618(3) $\AA$ ] [12], suggesting that the $\mathrm{O} \rightarrow \mathrm{Bi}$ intramolecular interaction of the latter is slightly weaker than that of the former. The acetate group in the organobismuth acetate, $\mathrm{O}\left(\mathrm{CH}_{2} \mathrm{C}_{6} \mathrm{H}_{4}\right)_{2} \mathrm{BiO}_{2} \mathrm{CCH}_{3}$ acts as an asymmetric bidentate ligand [Bi(1)-O(2) 2.237(8) $\AA$; $\mathrm{Bi}(1)-\mathrm{O}(2)$ 2.8857(9) $\AA$.

Acknowledgements: The work was supported by the Open Fund Project of Hunan Provincial Key Laboratory of Environmental Catalysis \& Waste Regeneration (Hunan Institute of Engineering) (2018KF08), and the Talent Research Startup Fund of Hunan Institute of Engineering (No. 14006).

\section{References}

1. Bruker. APEX2, SAINT and SADABS. Bruker AXS Inc., Madison, WI, USA (2009)

2. Sheldrick, G. M.: A short history of SHELX. Acta Crystallogr. A64 (2008) 112-122.

3. Sheldrick, G. M.: SHELXT - integrated space-group and crystalstructure determination. Acta Crystallogr. A71 (2015) 3-8.

4. Tan, N. Y.; Yin, S. F.; Li, Y. F.; Qiu, R. H.; Meng, Z. G.; Song, X. X.; Luo, S. L.; Au, C. T.; Wong, W. Y.: Synthesis and structure of an air-stable organobismuth triflate complex and its use as a high-efficiency catalyst for the ring opening of epoxides in aqueous media with aromatic amines. J. Organomet. Chem. 696 (2011) 1579-1583.

5. Toma, A.; Raţ, C. I.; Silvestru, A.; Rüffer, T.; Lang, H.; Mehring, M.: Heterocyclic bismuth(III) compounds with transannular $\mathrm{S} \rightarrow \mathrm{Bi}$ interactions. An experimental and theoretical approach. J. Organomet. Chem. 806 (2016) 5-11.

6. Ra t, C. I.; Silvestru, C.; Breunig, H. J.: Hypervalent organoantimony and -bismuth compounds with pendant arm ligands. Coord. Chem. Rev. 257 (2013) 818-879.

7. Tan, N. Y.; Chen, Y.; Yin, S. F.; Qiu, R. H.; Zhou, Y. B.; Au, C. T.: Synthesis and structures of hypervalent organoantimony and organobismuth chlorides containing asymmetric C,E,C-chelating $(\mathrm{E}=$ 0, S) ligands. Dalton Trans. 42 (2013) 9476-9481.

8. Tan, N. Y.; Chen, Y.; Zhou, Y. B.; Au, C. T.; Yin, S. F.: Synthesis and structure of organobismuth chlorides and triflates containing $(\mathrm{C}, \mathrm{E})$-chelating ligands $(\mathrm{E}=\mathrm{O}, \mathrm{S})$ and their catalytic application in the allylation of aldehydes with tetraallyltin. ChemPlusChem 78 (2013) 1363-1369.

9. Fridrichová, A.; Svoboda, T.; Jambor, R.; Padělková, Z.; Ružička, A.; Erben, M.; Jirásko, R.; Dostál, L.: Synthesis and structural study on organoantimony(III) and organobismuth(III) hydroxides containing an NCN pincer type ligand. Organometallics 28 (2009) 5522-5528. 
10. Liu, Y. P.; Lei, J.; Tang, L. W.; Peng, Y.; Au, C. T.; Chen, Y.; Yin, S. F.: Studies on the cytotoxicity and anticancer performance of heterocyclic hypervalent organobismuth(III) compounds. Eur. J. Med. Chem. 139 (2017) 826-835.

11. Tan, N. Y.; Wu, S. S.; Yang, H. Q.; Lan, D. H.; Au, C. T.; Yi, B.: Crystal structure of 6-cyclohexyl-6,7-dihydrodibenzo[c,f][1,5] azabismocin-12 (5H)-yl nitrate, $\mathrm{C}_{20} \mathrm{H}_{23} \mathrm{O}_{3} \mathrm{~N}_{2} \mathrm{Bi}$. Z. Kristallogr. NCS 234 (2019) 509-511.
12. Tan, N. Y.; Dang, L. M.; Lan, D. H.; Wu, S. S.; Au, C. T.; Yi, B.: Crystal structure of bis $\{5 \mathrm{H}$-dibenzo[c, $f][1,5]$ oxabismocin12(7H)-yl\} carbonate, $\mathrm{C}_{29} \mathrm{H}_{24} \mathrm{O}_{5} \mathrm{Bi}_{2}$. Z. Kristallogr. NCS 233 (2018) 875-877.

13. Nema, M. G.; Breunig, H. J.; Soran, A.; Silvestru, C.: Diorganobismuth(III) compounds with the pendant arm 2$\left(\mathrm{Me}_{2} \mathrm{NCH}_{2}\right) \mathrm{C}_{6} \mathrm{H}_{4}$ ligand - isothiocyanate, trifluoracetate and nitrate. J. Organomet. Chem. 705 (2012) 23-29. 